\title{
METODOLOGIA PARA IMPLANTAÇÃO DE PROGRAMAS DE PRESERVAÇÃO DE DOCUMENTOS DIGITAIS A LONGO PRAZO
}

\author{
Maurício Barcellos Almeida ${ }^{\mathrm{i}}$ \\ Beatriz Valadares Cendón ${ }^{\text {ii }}$ \\ Renato Rocha Souza ${ }^{\text {iii }}$
}

\begin{abstract}
Resumo: Um documento em papel se mantém por dezenas de anos mesmo sem cuidados muito especiais. Documentos criados por computador não possuem tal longevidade e evidências documentais essenciais para o funcionamento das instituições - legais, culturais ou históricas. Registrados em mídias digitais, estes podem desaparecer. A questão da preservação digital se apresenta como um problema real a ser solucionado pelas instituições, principalmente aquelas que têm por obrigação legal a manutenção de documentos a longo prazo, seja para atendimento a demandas do cidadão, seja para preservação da história institucional. O presente artigo se insere nesse contexto como uma iniciativa para orientar sobre a preservação digital em instituições públicas. Apresenta-se uma metodologia para criação de programas de preservação de documentos de arquivos em formato digital a longo prazo, bem como um exemplo de sua aplicação no âmbito do programa estadual. Esperase contribuir para o sucesso de iniciativas de preservação digital por meio da divulgação de princípios e fundamentos básicos.
\end{abstract}

Palavras-chave: Preservação digital. Arquivística. Documentos digitais.

\section{A METHODOLOGY FOR THE IMPLEMENTATION OF PROGRAMS FOR THE LONG TERM PRESERVATION OF DIGITAL DOCUMENTS}

\begin{abstract}
A paper document can be maintained for several years, even when it does not receive much proper treatment. Documents created via computers do not have such longevity and documental evidences which are crucial for the operation of the institutions - be they legal, cultural or historical ones. Recorded in digital media, those documents may disappear. The issue of digital preservation is a real problem for institutions, mainly for the ones in which the long term maintenance of documents is a legal obligation, either to support citizen's demands or to preserve the institutional history. This article is an initiative to guide public institution managers on dealing with digital preservation issues. Here is presented a methodology for creating long term digital preservation programs for archives, as well as an example of its application in the scope of a real situation. It is expected to contribute towards the success of digital preservation initiatives through the dissemination of related basic principles.
\end{abstract}

Keywords: Digital preservation. Archival. Digital Documents.

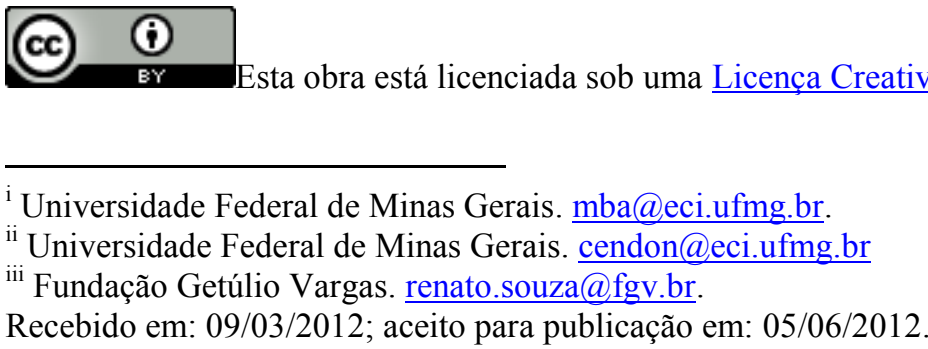

\footnotetext{
${ }^{\mathrm{i}}$ Universidade Federal de Minas Gerais. mba@eci.ufmg.br.

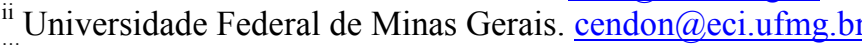

Recebido em: 09/03/2012; aceito para publicação em: 05/06/2012.
} 


\section{INTRODUÇÃO}

A questão da preservação de documentos de arquivo a longo prazo constitui-se em um problema que tem recebido atenção em todo o mundo nos últimos anos. Considerando o uso intensivo de documentos digitais na sociedade moderna, a importância do assunto reside na necessidade de preservar o patrimônio cultural e o saber da humanidade. Além disso, para fins institucionais e comerciais, existe a necessidade de manter documentos autênticos e acessíveis por um longo período, de forma a garantir direitos de cidadãos.

A dificuldade em preservar documentos digitais diz respeito à volatilidade das mídias utilizadas para registro dos dados e à rápida obsolescência da tecnologia. Por um lado, quando se avaliam problemas inerentes à preservação de registros em papel, a mídia digital parece ter características essenciais (BORGHOFF et al, 2003): i) sequências de bits podem ser guardadas por longos períodos de tempo, sem perda de dados; ii) grandes volumes de documentos são armazenados em pequeno espaço físico; iii) as buscas são rápidas e a recuperação eficiente; iv) a disseminação é feita via Internet e redes privadas. Por outro lado, o armazenamento digital é uma questão complexa, caracterizada por três problemas principais: i) interpretação dos dados: a mídia que registra os dados em formato digital não é diretamente legível para pessoas; ii) hardware: falhas e obsolescência nos dispositivos mecânicos e magnéticos tornam inevitável a perda de dados, mesmo se considerados os procedimentos para cópias de segurança; iii) software: a incompatibilidade entre formatos desenvolvidos ao longo dos anos, criados e manipulados por editores de texto variados e proprietários, dificultam o intercâmbio de documentos.

Um documento em papel pode ficar por anos em um local seco e escuro, sem maiores prejuízos à sua integridade. Documentos criados via computador não possuem tal longevidade, uma vez que os computadores apenas se mantém pelo auxílio ativo de pessoas. Sem tal auxílio, evidências documentais essenciais para o funcionamento das instituições, sejam legais, culturais ou históricas, são perdidas para sempre. A questão da preservação digital se apresenta, dessa forma, como um problema a ser solucionado pelas instituições, principalmente aquelas que têm por obrigação legal a manutenção de documentos a longo prazo, seja para atendimento a demandas do cidadão, seja para preservação da história institucional.

$\mathrm{O}$ presente artigo se insere nesse contexto como uma iniciativa para informar e orientar programas de preservação digital em instituições públicas. Para tal, apresenta-se 
metodologia para criação de programas de preservação de documentos de arquivos em formato digital em longo prazo. A metodologia reúne um conjunto de procedimentos genéricos - administrativos, arquivísticos, tecnológicos - que abrangem as necessidades básicas de preservação para diversos tipos de instituições. A metodologia foi testada em campo, no âmbito de um conjunto de ações para a modernização dos processos institucionais e aumento da capacidade gerencial do Governo do Estado de Minas Gerais. Apresentam-se como exemplo os resultados parciais de aplicação da metodologia no setor responsável pelas aposentadorias do estado.

Objetivando simplicidade, utiliza-se daqui em diante o termo "documento" para se referir a "documentos de arquivo" e o termo "preservação" para se referir a "preservação a longo prazo". O restante do presente artigo está organizado conforme segue: a seção 2 apresenta uma visão geral sobre a preservação digital, além de trazer exemplos de iniciativas nacionais e internacionais; a seção 3 apresenta a metodologia proposta, descrevendo os passos e fornecendo exemplos de uso; finalmente, a seção 4 apresenta as considerações finais e alternativas para trabalhos futuros.

\section{UMA VISÃO GERAL SOBRE PRESERVAÇÃO DIGITAL}

No processo histórico de disseminação da informação, a invenção da imprensa elevou significativamente a quantidade de registros escritos e promoveu uma verdadeira revolução social. O século XVIII assistiu à ascendência e ao domínio dos registros em papel, os quais ganharam força e independência nesse período (CLANCHY, 1993). No final do século XX, de forma similar, a emergência da Internet promoveu a produção e a disseminação em larga escala de registros digitais. Documentos digitais fazem parte do dia a dia das instituições.

A maioria dos documentos digitais, entretanto, não tem recebido qualquer tipo de tratamento visando à preservação. Isso ocorre mesmo considerando que parte significativa corresponde a documentos científicos e de valor histórico (UCLA, 2003). Problemas diversos dificultam tal tratamento, com destaque para a crescente dependência de fatores externos ao longo do ciclo de vida do documento. Os principais fatores intervenientes são hardware, software e mídia (THOMAZ, 2004).

Os procedimentos necessários inerentes à preservação digital são, na verdade, parte de políticas de informação, de gestão e de arquivo da instituição (BULLOCK, 1999; 
HEDSTROM, 1997). De fato, a adoção de um conjunto de técnicas básicas visando à preservação é apenas o primeiro passo de um longo processo, uma vez que a tecnologia é incapaz de proporcionar solução definitiva (DURANTI, 2007). As técnicas para preservação digital consistem de mecanismos que, em última instância, buscam combinar a estrutura lógica do registro ao seu suporte físico. As técnicas mais conhecidas são migração, emulação e encapsulamento (BORGHOFF et al, 2003).

A migração consiste em substituir o suporte de armazenamento e o software associado, antes que o documento se torne inacessível. Envolve abandonar certa tecnologia e todos os aspectos inerentes a ela, adotando outra, de uso corrente. Garante-se, assim, acesso a longo prazo com o acompanhamento da evolução tecnológica. O processo resulta em novos formatos de dados, o que torna necessário conhecer as características das mídias digitais de origem e de destino. A transferência de documentos entre mídias ocorre em períodos determinados em políticas institucionais, em geral não superiores a cinco anos.

A emulação propõe a criação de um software denominado emulador, o qual substitui o sistema em uso. A emulação dispensa a migração de software ao recriar o ambiente do sistema anterior, mas mantém a necessidade de migração do suporte. Requer metadados intrinsecamente ligados ao documento para que o emulador possa ler um arquivo escrito no sistema anterior. Não se trata de uma técnica de simples execução, uma vez que não é possível prever exatamente os metadados necessários e nem o curso das mudanças tecnológicas (LUSENET, 2002).

O encapsulamento consiste em reunir em um mesmo dossiê o conjunto de softwares e a descrição das condições necessárias para a reprodução do documento a ser preservado. No processo de encapsulamento, a seleção dos documentos a se preservar requer critérios bem definidos, assim como a definição dos formatos utilizados para preservação. O encapsulamento envolve algum tipo de migração. Trata-se de uma alternativa adequada para a preservação de documentos digitais complexos, portadores de anexos ou hiperlinks, como ocorre na Web. Para que o processo seja bem sucedido, identificam-se os elementos participantes da rede de conexões e encapsulam-se os recursos necessários para a visualização do conjunto.

Além das técnicas citadas, padrões de metadados são requisitos básicos para definir o contexto de caracterização do documento, atributo essencial para garantir acesso em longo prazo (IKEMATU, 2001). Diversas iniciativas internacionais para preservação digital adotam 
metadados como instrumento de preservação. No restante da presente seção, descrevem-se brevemente algumas dessas iniciativas, sem a pretensão de apresentar uma pesquisa exaustiva.

\section{Metadata Requirements Project ${ }^{3}$}

Trata-se de uma iniciativa desenvolvida na University of Pittsburgh, que propõe um modelo de referência para intercâmbio de registros visando à preservação digital no contexto dos negócios. O conjunto de metadados definido possibilita acesso seguro a documentos de transações comerciais e, portanto, lhes atribui valor de prova legal, por um longo período de tempo. Os metadados foram organizados em um modelo de referência composto pelos seguintes módulos funcionais: organização, sistemas, aquisição de registros, utilização e manutenção (BEARMAN;SOCHATS, 2004).

\section{Dublin Core Metadata Initiative ${ }^{4}$ (DMCI)}

Metadados criados automaticamente podem ser tornar ambíguos em função de alterações no ambiente da instituição. Na tentativa de minimizar o problema, a DMCI propõe um conjunto mínimo de atributos para descrever cada elemento de metadados. Definem-se termos para fins diversos: i) termos básicos para descrição, como: nome, etiqueta de identificação, identificador $W e b$, definição etc. ii) termos de descrição adicionais, como: comentário, referências, domínio, versão, dentre outros; e iii) termos para definição de contexto, como: esquemas de vocabulário, sintaxe de esquemas de classificação, classes, vocabulário de tipos, dentre outros (DMCI, 2004).

\section{Open Archives Information System Reference Model ${ }^{5}$ (OAIS)}

O OAIS é aplicável a qualquer tipo de documento digital. As relações entre os produtores de informação e os consumidores de informação são determinadas em uma política denominada gestão da interação. Essa política estipula em que condições um consumidor tem acesso a dados; define níveis de acesso e privilégios, e avaliam questões de sigilo. No âmbito do OAIS, dados em formato digital são armazenados em uma sequência codificada, a qual é interpretada por esquemas de representação. $\mathrm{O}$ conjunto composto por dados, codificação e representação da informação constitui um objeto digital, o qual, uma vez acessível, é então preservado (CCSDS, 2002).

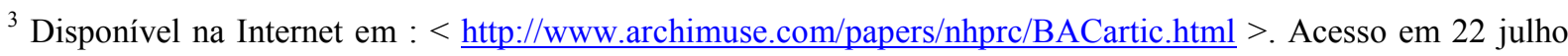
de 2010.

${ }^{4}$ Disponível na Internet em : $<$ http://dublincore.org/>. Acesso em 22 Julho de 2010.

${ }^{5}$ Disponível na Internet em : $<$ http://public.ccsds.org/publications/RefModel.aspx $>$. Acesso: 22 Julho 2011.
} 


\section{CURL Exemplars in Digital Archives Project ${ }^{6}$ (CEDARS)}

O CEDARS é uma iniciativa de um consórcio universitário inglês (CEDARS, 2002), que resultou em protótipo de um sistema baseado no OAIS. Possui dois desdobramentos principais: o primeiro lida com o direito de propriedade intelectual no contexto de trabalho de bibliotecários e arquivistas; o segundo, sobre estratégias, considera que a preservação digital envolve preservar o acesso, a qual, por sua vez, envolve agregar metadados (de preservação, de migração, de contexto, dentre outros).

\section{Preservation Metadata for Digital Collections Initiative ${ }^{7}$ (PMDC)}

Trata-se de um projeto da National Library of Australia (NLA, 1999) que objetiva manipular, para fins de preservação, coleções e documentação de bibliotecas, arquivos de publicações digitais on-line, publicações digitais e coleções (digitais ou analógicas) de áudio, coleções de textos e imagens. O PMDC também é baseado no OAIS: metadados descrevem pacotes de informação e a história dos objetos no processo de preservação.

\section{Metadata Encoding and Transmission Standards ${ }^{8}$ (METS)}

Trata-se de uma iniciativa desenvolvida pelo Network Development and MARC Standards Office da U.S. Library of Congress (CUNDIFF, 2004). A METS se fundamenta no padrão OAIS e propõe um padrão de metadados em formato Extended Markup Language (XML) para gerenciar coleções de objetos digitais. Esté é um padrão para codificação descritiva, administrativa e estrutural de metadados que foi especificamente criado para bibliotecas digitais, o que possibilita produção de conjuntos padronizados de metadados.

\section{Norma Brasileira de Descrição Arquivística (NOBRADE) ${ }^{9}$}

A mais importante iniciativa brasileira sobre preservação no âmbito da arquivística baseia-se na International Standard Archival Description (ISAD), um padrão internacional traduzido para o português pelo Conselho Nacional de Arquivos sob a denominação de Norma Geral Internacional de Descrição Arquivística (ISAd). A iniciativa herda da ISAD a

\footnotetext{
${ }^{6}$ Disponível na Internet em $:<$ http://www.ukoln.ac.uk/services/elib/projects/cedars/>. Acesso em 22 Julho 2010.

${ }^{7}$ Disponível na Internet em : $<$ http://www.nla.gov.au/preserve/pmeta.html $>$. Acesso em 22 Julho 2010.

${ }^{8}$ Disponível na Internet em : $<$ http://www.loc.gov/standards/mets/>. Acesso em 22 julho de 2010.

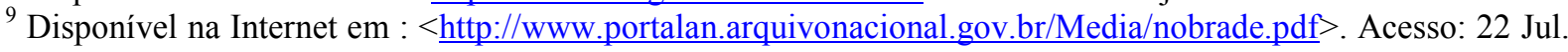
2011. 
estrutura hierárquica baseada em princípios de proveniência e organicidade, de suma importância na teoria arquivística.

\section{METOdologia PARA CRIAÇÃo DE PROGRAMAS DE PRESERVAÇÃo DIGITAL}

O processo de planejar um programa de preservação digital, considerando um ambiente heterogêneo de instituições públicas, é complexo e demanda organização. Visando organizar esforços e ações nesse sentido, propõe-se uma metodologia sistemática. Nesta seção, descreve-se o contexto de criação da metodologia e seus principais procedimentos. Além disso, apresentam-se como exemplo os resultados parciais da aplicação desta a uma instituição pública, que resulta em um procedimento geral para seleção de formatos para documentos digitais.

\subsection{Contexto}

A preservação digital envolve o conjunto de ações que permite assegurar o acesso a recursos digitais por um determinado período. Em situações reais, os recursos digitais para preservação podem ser estáticos ou dinâmicos; podem estar em uma variedade de formas, desde simples documentos de texto até complexos recursos Web que combinam sons e imagens. Os documentos digitais podem ainda estar em formato físico, ou seja, aqueles que foram impressos; podem ser substitutos digitais, criados como resultado da conversão para a forma digital análoga (imagens digitalizadas); e podem ser registros natidigitais, criados diretamente em mídia digital no dia a dia das organizações e existentes apenas nesse meio (emails, páginas $W e b$ dinâmicas etc.).

De forma a possibilitar a gestão efetiva dessa variedade de documentos digitais, no contexto de modernização administrativa promovido pela Secretaria de Planejamento e Gestão do Estado de Minas Gerais, foi proposto um programa que permitirá às instituições estaduais atuar sistematicamente sobre a produção, manutenção e preservação dos documentos digitais, sejam eles natidigitais ou resultado da conversão. O programa, que define os procedimentos a serem seguidos nas instituições é denominado, aqui, Programa para Preservação Digital (PPD). Dada a complexidade em implantar o PPD nas diversas unidades 
do Governo do Estado de Minas Gerais, foi proposta uma metodologia que descreve diretrizes de alto nível para preservação digital. A aplicação da metodologia foi planejada para as instituições estaduais que, por interesse ou por exigência legal, tenham necessidade de manipular e de preservar registros digitais a longo prazo.

A metodologia é baseada em fundamentos da arquivística (INTERPARES, 2001), de programas de garantia de qualidade (ISO, 2008) e gestão (ALMEIDA; NEVES; TEIXEIRA, 2008). Consiste em um conjunto de procedimentos sistemáticos e de um conjunto de documentos que reúnem requisitos mínimos necessários para que um programa de preservação digital possa ser implementado.

\subsection{A metodologia para implantação de programas de preservação digital}

A metodologia é composta por um conjunto de procedimentos que resultam em uma estrutura administrativa autossustentável para o programa. Essa estrutura é composta por órgãos executivos e normativos, equipe de implantação e gestão, documentos de controle, requisitos técnicos, dentre outros. Os principais procedimentos da metodologia, detalhados no restante da presente seção, são apresentados a seguir:

a) Apresentação do PPD na instituição;

b) Estabelecimento de princípios para o PPD na instituição;

c) Definição da estrutura gerencial do PPD;

d) Definição de alçadas e autoridade;

e) Definição de documentos de controle do PPD;

f) Recursos para manutenção do PPD;

g) Estabelecimento de requisitos para implantação do PPD na instituição.

\section{a) Apresentação do PPD na instituição}

O PPD se fundamenta em princípios de qualidade total e compreende a implantação, manutenção e melhoria contínua de ações de preservação de recursos digitais em instituições públicas. A implantação das ações não é obrigatória e é realizada de acordo com as exigências legais ou com os interesses de cada instituição, a qual deve, nesse caso, solicitar apoio institucional, técnico e arquivístico.

Uma vez decidida a implantação, a apresentação do programa e de suas diretrizes básicas se faz necessária. Essa apresentação envolve, no mínimo, esclarecer na instituição 
sobre: delimitação do escopo do programa na instituição, descrição das instâncias diretivas, criação de comissões e estabelecimento de documentos de controle.

Qualquer instituição do estado, órgão, unidade (ou parte destes) pode requisitar a implantação do programa. Ao solicitar a implantação, a instituição recebe apoio técnico e gerencial para criar comissões, adotar procedimentos técnicos e realizar auditorias. Esse apoio é fornecido pelas instâncias diretivas do programa.

As instâncias diretivas das comissões (instância superior e órgão normativo) são responsáveis pela coordenação geral do programa e pela busca por melhorias contínuas nos procedimentos. Isso é feito através da disseminação dos princípios do programa, da elaboração e da revisão de seus objetivos e metas, dos resultados de auditorias, da análise de dados nas diversas fases da implantação, de ações corretivas e preventivas, e da análise crítica dos resultados.

As comissões nomeadas no âmbito do programa definem escopos específicos de implantação, os quais orientam a gestão do programa nas instituições em que este foi implantado ou naquelas em que a implantação está em andamento. Uma vez implantado, o programa é autossustentável, pois prevê auditorias e renovação da aprovação apenas para instituições que foram capazes de manter os princípios.

A gestão do programa pelas comissões se dá através de um conjunto de documentos de controle, os quais especificam e operacionalizam princípios, recursos, requisitos, dentre outros. Tal conjunto de documentos é constantemente revisto e atualizado, num processo interativo para melhoria contínua, de forma a manter o conjunto de procedimentos e de recomendações do PPD alinhado à realidade das instituições.

\section{b) Estabelecimento de princípios para o PPD na instituição}

Recursos digitais exigem gestão e cuidados desde o momento de sua criação, o que pode ser feito através de princípios amplamente disseminados pela instituição. Tais princípios vão assegurar a preservação em longo prazo e estão distribuídos em diferentes horizontes temporais: estratégicos (longo prazo), táticos (médio prazo) e operacionais (curto prazo). Cada instituição deve propor um conjunto especifico que atenda a sua realidade, mas um conjunto genérico de princípios é parte obrigatória do programa. Esse conjunto genérico é apresentado a seguir: 
- Princípios estratégicos:

- necessidade de salvaguarda de registros vitais para manutenção das funções de negócios e para tomada de decisão;

- atendimento as suas obrigações legais e culturais;

- necessidade de racionalização da gestão dos documentos digitais;

- necessidade de compartilhamento e reúso da informação;

- garantia de acesso à informação para usuários e cidadãos;

- atendimento as suas obrigações legais e culturais, bem como de acesso a material digital histórico.

- Princípios táticos:

- necessidade de disseminação, por toda a instituição, dos benefícios do investimento na gestão dos documentos digitais;

- necessidade de assegurar que a informação é confiável e autêntica;

- necessidade de reduzir custos de acesso a documentos disponibilizadosa longo prazo;

- possibilidade de acesso eficiente a documentos e à informação;

- importância da proteção do investimento em tecnologia da informação;

- importância da segurança da informação via controle de acesso.

- Princípios operacionais:

- necessidade de acesso a documentos digitais;

- necessidade de planejamento para volumes de dados futuros;

- necessidade de racionalização dos recursos financeiros aplicados em tecnologia (documentos organizados e preservados geram agilidade).

c) Definição da estrutura gerencial do PPD

A implantação e gestão do PPD, bem como a concepção de seus princípios e diretrizes, está estruturada em comissões representadas na Figura 1: 


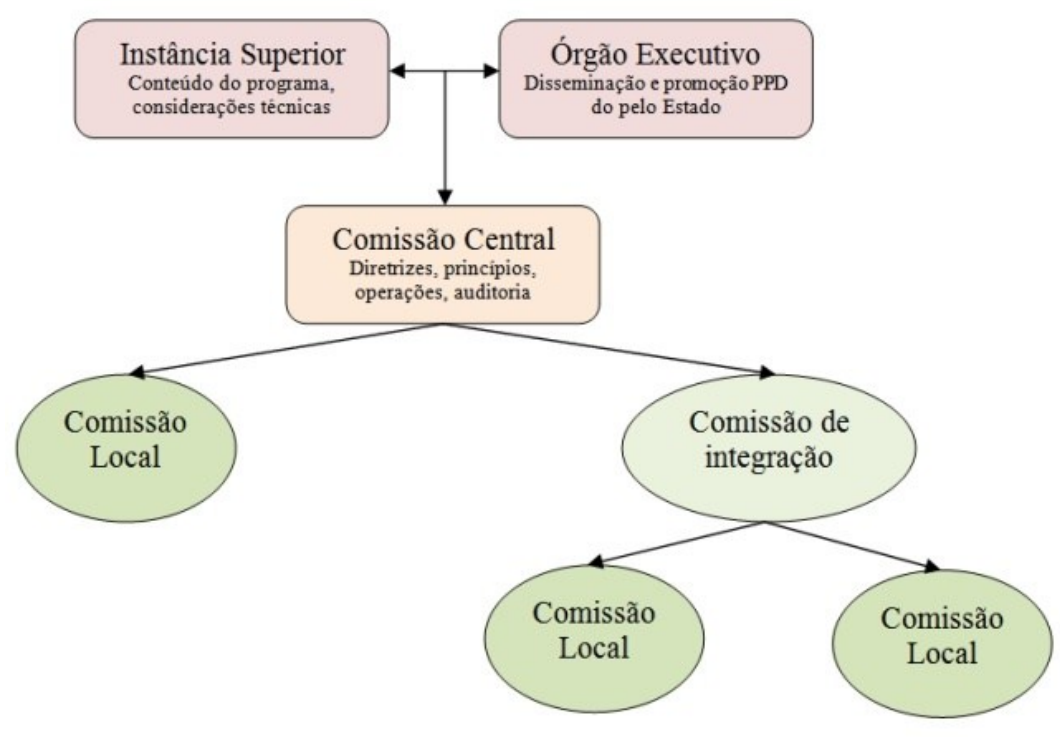

Figura 1: comissões que compõem a estrutura do programa

Tal estrutura se sobrepõe à estrutura gerencial de cada instituição em que o programa está sendo implantando. Minimamente, consideram-se envolvidas as seguintes comissões:

- Uma instância superior, que decide sobre o conteúdo técnico do programa (por exemplo, o arquivo público estadual ou órgão equivalente);

- Um órgão executivo (por exemplo, uma secretaria de estado) com atribuição para promover e para assessorar a implementação do PPD em instituições;

- Uma Comissão Central responsável pela disseminação das diretrizes e políticas relativas à preservação digital, bem como pelas auditorias de implantação e de manutenção;

- A Comissão Central se relaciona com as Comissões de Integração, as quais, por sua vez, consistem em um conjunto de Comissões Locais;

- A Comissão Local representa uma instituição, ou parte dela, com os limites definidos no escopo em que o programa é implantado, mantido e verificado.

As comissões são compostas por membros de cada instituição que implanta o programa, os quais, além de suas atribuições normais, assumem papeis no âmbito do programa. Esses papeis resultam em uma estrutura de alçada, autoridades e funções do PPD.

\section{d) Definição de alçadas e autoridade}

As comissões criadas têm funções específicas no âmbito do programa. Têm autoridade para agir e alçadas que limitam tais ações. A estrutura de uma comissão é apresentada na 
Figura 2. As alçadas referentes às instituições e comissões envolvidas são apresentadas na Figura 3.

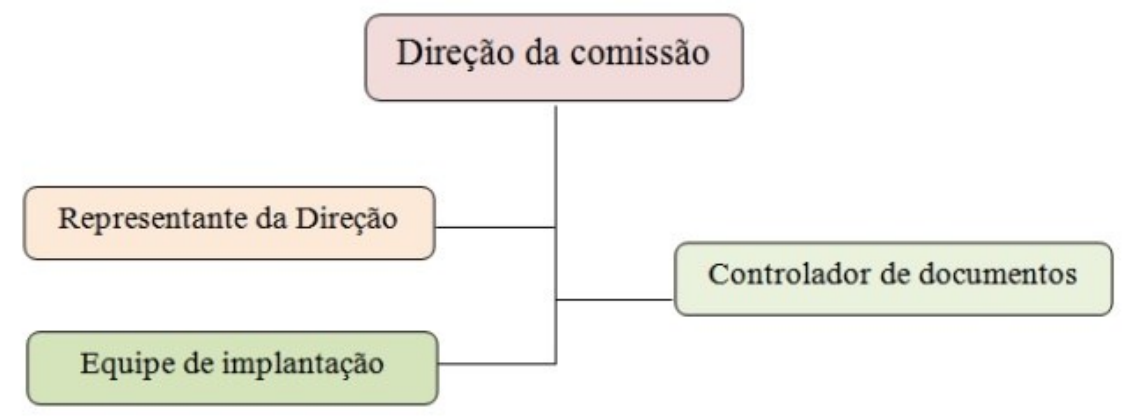

Figura 2: cargos que compõem a estrutura de uma comissão

Cada comissão possui pelo menos um diretor, um representante da direção, um controlador de documentos e uma equipe de implantação. A direção da comissão, em geral, é atribuída a um gerente da instituição que implanta o programa. Dessa forma, envolve-se a alta gerência da desta garantindo o apoio necessário para a implantação dos procedimentos. Como a direção da comissão sobrepõe-se a cargos de gerência na instituição, ela é representada nas reuniões e auditorias por um representante da comissão. O controlador de documentos controla, atualiza e dissemina os documentos de controle que fazem parte do programa, ou seja, aqueles documentos que garantem o funcionamento do programa, e não os selecionados para preservação. A equipe de implantação é variável e é responsável por implementar o programa no escopo definido.

\begin{tabular}{|l|c|c|c|c|}
\hline \multicolumn{1}{|c|}{ Função } & \multicolumn{5}{c|}{ Tipo de documento de controle } \\
& $\begin{array}{c}\text { Manual do } \\
\text { programa }\end{array}$ & $\begin{array}{c}\text { Procedimento } \\
\text { Geral }\end{array}$ & $\begin{array}{c}\text { Procedimento } \\
\text { Específico }\end{array}$ & $\begin{array}{c}\text { Instrução } \\
\text { Normativa }\end{array}$ \\
\hline Instância superior & $\mathrm{A}$ & $\mathrm{A}$ & & \\
\hline Órgão executivo & $\mathrm{A}$ & $\mathrm{A}$ & $\mathrm{V} / \mathrm{A}$ & $\mathrm{V} / \mathrm{A}$ \\
\hline Comissão Central & $\mathrm{E} / \mathrm{V}$ & $\mathrm{E} / \mathrm{V}$ & $\mathrm{E} / \mathrm{V}$ & $\mathrm{E} / \mathrm{V}$ \\
\hline Comissão local & & & $\mathrm{E} / \mathrm{V}$ & $\mathrm{E} / \mathrm{V}$ \\
\hline Equipe de implantação & & & & \\
\hline
\end{tabular}

Figura 3: alçadas no âmbito do programa 
e) Definição de documentos de controle do PPD

Os documentos de controle formam um conjunto que permite gerir o PPD em muitas instituições simultaneamente. Através desses documentos especiais é possível gerenciar o programa a partir de um pequeno número de padrões e controles.

O documento primário é o Manual do Programa (MP), em que são definidas as características de todos os documentos de controle e das comissões, bem como todos os outros recursos necessários para manutenção do programa. Os Procedimentos Gerais (PGs) contêm as diretrizes globais para atender aos requisitos do PPD em cada instituição, em particular. Caso algum detalhe não esteja contemplado no Procedimento Geral, as comissões providenciam a elaboração de Procedimentos Específicos (PEs), desde que não conflitantes com os documentos de nível superior no âmbito do programa.

Além dos Procedimentos Específicos, comissões locais emitem Documentos Complementares, como por exemplo, as Instruções de Trabalho, caso seja necessário detalhar alguma especificidade de uma instituição ou processo. Os registros dos documentos de controle são armazenados e mantidos acessíveis para qualquer membro da comissão.

\begin{tabular}{|c|c|}
\hline Documento de controle & Utilização no programa \\
\hline Manual do Programa & Especificar o PPD. \\
\hline Procedimentos Gerais (PGs) & $\begin{array}{l}\text { Descrever as atividades e os processos gerais necessários para } \\
\text { a implantação do PPD. }\end{array}$ \\
\hline Procedimentos Específicos (PEs) & $\begin{array}{l}\text { Descrever as atividades e processos específicos para a } \\
\text { implantação do PPD, em uma instituição. }\end{array}$ \\
\hline Instrução de trabalho & $\begin{array}{l}\text { Documentar de forma detalhada as atividades ou fornecer } \\
\text { dados para sua execução. }\end{array}$ \\
\hline Documentos complementares & Documentar de forma complementar as atividades. \\
\hline
\end{tabular}

Figura 4: hierarquia de documentos do programa

\section{f) Recursos para manutenção do PPD}

A direção de cada comissão é responsável pela identificação e pela provisão de recursos que vão garantir a correta implementação dos princípios e dos requisitos do programa, na esfera de atuação de cada uma daquelas e de acordo com suas alçadas. Nesse contexto, destacam-se os recursos utilizados para: 
- a implementação e manutenção dos procedimentos e atividades relativas ao PPD, bem como aquelas que promovam sua melhoria contínua;

- o comprometimento dos recursos humanos envolvidos com os procedimentos acordados, inclusive liberação para dedicação ao programa e para treinamento;

- a garantia de que os recursos humanos possuem competências apropriadas para as tarefas necessárias;

- o atendimento a orientações de instâncias superiores no âmbito do PPD, bem como a legislação pertinente;

- investimentos financeiros, humanos, em infraestrutura e em condições de trabalho adequadas para atender os requisitos do programa;

- melhorias no relacionamento com usuários, cidadãos e outras instituições do estado, através do melhor atendimento às suas necessidades.

A provisão de recursos financeiros impacta diretamente no sucesso do programa. Os custos de preservação não são totalmente independentes daqueles que possibilitam acesso ao documento. Esses custos de acesso podem crescer rapidamente em função da velocidade da mudança tecnológica e das expectativas dos usuários em relação a essas mudanças, além de novos requisitos legais. A direção das comissões deve estar atenta a fatores que afetam os recursos e os montantes de investimentos necessários para preservação. Exemplos desses recursos, os quais devem ser considerados minimamente em qualquer PPD, são:

- a quantidade dos recursos digitais que requerem preservação;

- o escopo e a complexidade dos formatos;

- o nível de controle requerido sobre os recursos digitais;

- o padrão de acesso necessário para atender aos objetivos da organização;

- o grau de padronização dos recursos digitais na organização;

- a necessidade de gerenciar mudanças tecnológicas ao longo do tempo;

- a necessidade de equilibrar custos de preservação digitais e tradicionais.

\section{g) Estabelecimento de requisitos para implantação do PPD na instituição}

Os requisitos do PPD são descritos em PGs, que são os documentos de controle que orientam a implantação e a manutenção do programa. Cada PG abrange um assunto específico e relevante para os objetivos do programa. A Figura 5 apresenta os PGs que se aplicam ao PPD. Em seguida, um breve descritivo do assunto de cada PG é apresentado. 


\begin{tabular}{|c|l|}
\hline PG-01 & Requisitos para projeto, implementação e manutenção de documentos em formato digital. \\
\hline PG-02 & Avaliação de documentos digitais para preservação a longo prazo. \\
\hline PG-03 & Seleção de documentos digitais para preservação permanente. \\
\hline PG-04 & Acesso a documentos preservados. \\
\hline PG-05 & Recuperação de registros. \\
\hline PG-06 & Auditoria e controle. \\
\hline PG-07 & Formatos para documentos digitais. \\
\hline PG-8 & Auditoria e verificação do programa. \\
\hline
\end{tabular}

Figura 5: PGs utilizados no PPD

$\underline{\text { PG-1) Requisitos para projeto, implementação e manutenção de documentos digitais }}$

Os documentos em formato digital devem ser gerenciados ao longo de todo o seu ciclo de vida, de forma a assegurar acessibilidade e legibilidade. Para isso, é necessário que a forma, o conteúdo e os relacionamentos do documento não sejam alterados durante seu ciclo de vida e período de guarda. A gestão dos documentos digitais requer visão sistêmica sobre o conjunto de fases da existência do documento, quais sejam: geração, manutenção, avaliação, descarte ou preservação de longo prazo.

O PG-1 enfatiza o conjunto de funções exigidas para preservação, abrangendo os requisitos para produção, manutenção e preservação de registros autênticos. Tais funções possibilitam o desenvolvimento, o projeto, a manutenção e a implementação da estrutura responsável pela gestão das atividades de preservação em uma instituição. As atividades são essenciais para a implantação do programa, fornecendo subsídios para: adeterminação do escopo do programa; o planejamento dos recursos financeiros, tecnológicos e de informação; a identificação dos documentos e das fontes originais; o planejamento da produção de documentos; os procedimentos-padrão de projeto, implementação e manutenção; as estratégias de manutenção.

\section{PG-2) Avaliação de documentos digitais para preservação a longo prazo}

A programação de retenção de documentos possibilita a tomada de decisão sobre o descarte ou a preservação, a qual é gerenciada por procedimentos de manutenção. Avaliações podem também ser conduzidas quando da necessidade de definição sobre o descarte de documentos específicos. 
O PG-2 enfatiza o conjunto de funções exigidas para avaliação de documentos digitais que serão os objetos de preservação. Permite o planejamento de atividades essenciais para o programa em cada instituição, fornecendo subsídios para: avaliação preliminar; identificação dos produtores de documentos; avaliação de autenticidade; documentação da avaliação de autenticidade; monitoramento de documentos; reavaliação periódica; identificação dos componentes de um documento digital; e avaliação da viabilidade da preservação.

\section{PG-3) Seleção de documentos digitais para preservação permanente}

A seleção e a aquisição de documentos, bem como todas as atividades subsequentes, objetivam manter a autenticidade de acessibilidade dos documentos objeto de preservação. $\mathrm{O}$ processo de transferência de custódias entre produtor e preservador é essencial para o programa.

O PG-3 enfatiza o conjunto de funções exigidas para aquisição de registros digitais objeto da preservação. Permite o planejamento de atividades essenciais para o programa em cada instituição, fornecendo subsídios para: elaboração do plano de transferência; definição de procedimentos-padrão para transferência; identificação de formatos; tratamento de redundâncias; processamento dos documentos.

\section{$\underline{\text { PG-4) Acesso a registros digitais preservados }}$}

O preservador é a entidade responsável pela custódia legal e física, preservação, proteção e acesso aos documentos provenientes de um produtor. O preservador exerce o papel de custodiante seguro dos registros do produtor. As cópias autênticas dos documentos são mantidas pelo custodiante no sistema de preservação, o qual inclui a descrição dos documentos e o sistema de recuperação. O sistema de preservação mantém regras para produção de cópias autênticas, em caso de obsolescência tecnológica.

O PG-4 enfatiza o conjunto de funções exigidas para acesso a documentos digitais preservados. Permite o planejamento de atividades essenciais para o programa em cada instituição, fornecendo subsídios para: descrição dos documentos; identificação de requisitos legais; estratégias para manutenção de documentos; manutenção dos recursos de armazenamento. 


\section{$\underline{\text { PG-5) Recuperação de documentos digitais preservados }}$}

A possibilidade de se acessar continuamente documentos é característica importante de qualquer programa de preservação. $\mathrm{O}$ acesso aos documentos preservados é componente essencial em um programa de preservação digital.

O PG-5 enfatiza o conjunto de funções exigidas para a recuperação de documentos digitais preservados, que é gerenciada pelo preservador. Permite o planejamento de atividades essenciais para o programa em cada instituição, fornecendo subsídios para: definição de diretrizes para produção de cópias de documentos; diretrizes técnicas para formatos, equipamentos e softwares.

\section{PG-6) Auditoria e controle de repositórios digitais}

A função de auditoria e certificação de repositórios digitais envolve mais do que a simples documentação dos critérios utilizados. Um processo completo de certificação fornece ferramentas para planejamento dos procedimentos, bem como para verificação de sua conformidade do ponto de vista interno e externo. O processo de auditoria e controle é construído na instituição de forma interativa e recursiva, uma vez que nenhuma instituição de padronização possui todas as ferramentas necessárias e um processo de avaliação completo. Uma prática corrente é a identificação de padrões relevantes para cada comunidade usuária do repositório.

O PG-6 enfatiza o conjunto de funções exigidas para auditoria e controle sobre repositórios que armazenam documentos digitais preservados. Permite o planejamento de atividades essenciais para o programa em cada instituição, fornecendo subsídios para: organização do repositório; definição de funções, processos e procedimentos; identificação da comunidade e dos usos pretendidos para os documentos; e para verificação da infraestrutura técnica e tecnológica.

\section{$\underline{\text { PG-7) Formatos para registros digitais }}$}

As funções para definição de formatos de arquivos adequados ao programa em cada instituição estão relacionadas à avaliação de fatores previamente definidos. O PG-7 enfatiza o conjunto de funções exigidas para seleção de formatos digitais. Permite o planejamento de atividades essenciais para o programa em cada instituição, fornecendo subsídios para: identificação e descrição de um formato, fatores de sustentabilidade; fatores de qualidade e funcionalidade; formatos recomendados para preservação de imagens e texto. 


\section{$\underline{\text { PG-8) Auditoria e verificação do programa de preservação }}$}

O planejamento, a execução e a descrição dos resultados de verificações e auditorias determinam se o programa está em conformidade com documentos regulatórios, com a legislação estadual, com as normas nacionais e internacionais e com o manual do programa de gestão, dentre outros constantes no planejamento do programa.

\subsection{Exemplo de aplicação}

Nesta seção, apresenta-se o detalhamento de um PG no setor responsável pelos processos de aposentadoria de servidores estaduais. O acervo objeto do PPD contém documentos de caráter intermediário, ou seja, um conjunto de documentos com baixo índice de consulta pela Secretaria de Planejamento. No entanto, esse conjunto de documentos ainda não havia perdido o seu valor de prova jurídica. Além disso, os documentos possuíam longo prazo precaucional de guarda, antes que pudessem ser eliminados ou recolhidos a um arquivo de guarda permanente. A decisão por digitalizar o acervo se baseou na dificuldade de recuperação da informação em papel: em alguns casos, eram necessários cerca de 15 dias para localizar um processo de aposentadoria de um servidor, o que resultava em um atendimento deficiente ao cidadão.
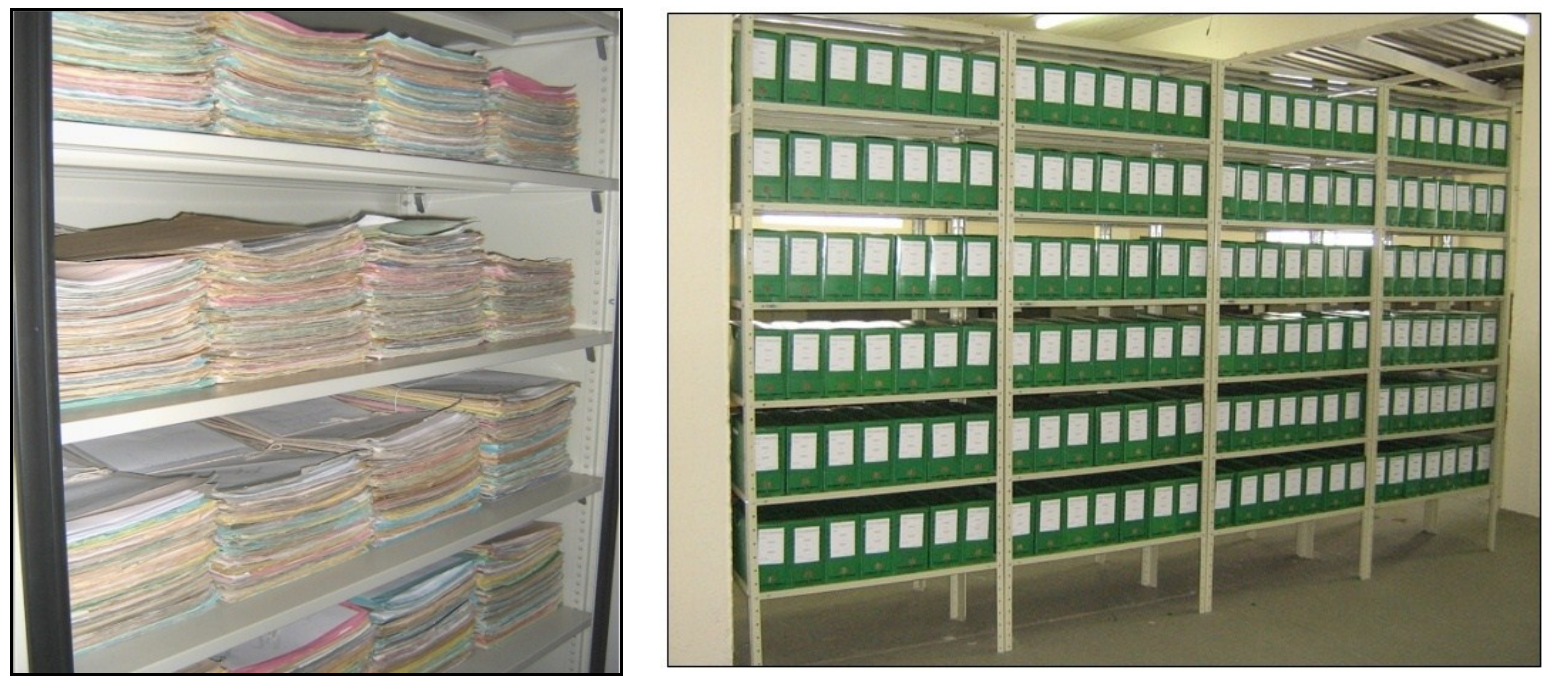

Figura 6: parte do acervo (cerca de 500ml) aguardando digitalização

O PG-7 versa sobre formatos para documentos digitais e foi escolhido como exemplo por sua importância no contexto do programa. Um PG é estruturado de acordo com os seguintes itens: objetivos, aplicações, referências, alçada e autoridade, definições, funções e 
atividades, registros de controle, glossário e anexos. Cada um desses itens está detalhado em seguida, da forma como consta no procedimento original do órgão mencionado.

PG-7. Formatos para registros digitais na Diretoria Central de Contagem de Tempo e Aposentadoria (DCCTA)

Objetivos:

Os formatos de arquivos estão sujeitos à evolução constante e, assim, à rápida obsolescência tecnológica. $\mathrm{O}$ processo de seleção de formatos para preservação deve considerar as possibilidades para redução dos riscos relativos a custos, como por exemplo, o uso de formatos: bem documentados; já testados e amplamente adotados; passíveis de utilização em diferentes plataformas de software e hardware, dentre outras. Tais considerações objetivam minimizar a frequência de migração, reduzindo, assim, os custos de preservação. O propósito da migração é preservar a integridade dos objetos digitais e manter a possibilidade de recuperação, apresentação e acesso face a constante mudança tecnológica. $\mathrm{O}$ PG-7 enfatiza um conjunto de funções relacionadas à migração e a recomendações para formatos de arquivos. Permite o planejamento de atividades essenciais para o programa em cada instituição, fornecendo subsídios para o planejamento da estratégia de preservação e para a definição dos formatos de arquivos digitais.

Aplicações:

Esse PG se aplica a todas as Comissões Locais e Comissões de Integração as quais estão em processo de implantação do PPD, ou que já se encontram em processo de auditoria.

\section{Referências:}

Os seguintes documentos são referências para o PG-7 e devem ser consultados em caso de dúvidas:

- Manual do Programa de Preservação Digital;

- Procedimento Geral: requisitos para projeto, implementação e manutenção de documentos em formato digital;

- Procedimento Geral: avaliação de documentos em formato digital para preservação a longo prazo;

- Procedimento Geral: seleção de documentos digitais para preservação;

- Procedimento Geral: acesso a documentos preservados;

- Procedimento Geral: recuperação de registros digitais preservados;

- Procedimento Geral: auditoria e controle de repositórios digitais; 
- Documentos regulatórios e normas do APM;

- Documentos regulatórios e legislação estadual;

- Normas nacionais e internacionais.

\section{Alçada e autoridade}

\begin{tabular}{l|l}
\multicolumn{1}{c|}{ Atividade } & \multicolumn{1}{c}{ Responsável } \\
\hline Critérios para seleção de formatos - migração & Direção da Comissão Central \\
\hline Definição de fatores de sustentabilidade & Direção da Comissão Local \\
\hline Definição de fatores de qualidade e de funcionalidade & Direção da Comissão Local \\
\hline Definição dos formatos para preservação & Direção da Comissão Central
\end{tabular}

Definições

Essa seção contém todas as definições necessárias para especificar as funções e atividades contidas no PG, por exemplo:

- codificação bit-stream: elemento que, quando capturado e armazenado em uma mídia de armazenamento digital, gera um arquivo de computador.

- imagens mapeadas em bits (bit-mapped): tipo de formato de arquivo para imagens usado para guardar imagens digitais.

- marcação: consiste em marcas feitas em um texto eletrônico para indicar a forma de apresentação ou a estrutura do conteúdo.

- migração: consiste na transferência periódica de materiais em formato digital de uma configuração de hardware e software para outra, ou de uma tecnologia de computadores para a geração subsequente.

\section{Funções e atividades}

A instituição deve identificar formatos de arquivos preferenciais para transferência, armazenamento, busca e manipulação por usuários, bem como para atender a requisitos de preservação a longo prazo. No planejamento, distingue-se entre formatos ou versões usadas para arquivamento e para acesso, a partir de diferentes requisitos. Por exemplo, uma imagem de alta resolução é armazenada em formato TIFF no caso de arquivamento e preservação a longo prazo; e em formato JPEG quando se busca acesso e distribuição via rede. 
Existe um grande número de formatos digitais no dia a dia das instituições, de forma que se torna tarefa complexa selecionar um ou outro sem considerar o contexto corrente e as particularidades de cada instituição. A escolha do formato está relacionada as possibilidades de uso de estratégias de preservação a longo prazo, em especial, a migração. Recomendações mínimas devem ser consideradas.

\section{$\underline{\text { A - Recomendações para migração e formatos }}$}

Existem várias possibilidades de migração entre hardware, software e mídias. Interessam, aqui, aquelas relacionadas a textos em documentos de arquivo. O processo de migração deve garantir que a qualquer tempo, para qualquer documento arquivado, exista pelo menos uma plataforma de hardware e software atualizada que permita acessar, interpretar e representar o documento.

\section{A.1-Critérios básicos para seleção de formatos com vistas a processos de migração}

- O formato de dados deve ser público, isto é, com semântica e sintaxe definidas, documentado e acessível;

- O formato de dados deve ser padronizado por uma organização de renome (por exemplo, organizações internacionais como a Internacional Organization for Standardization, American National Standard for Information Sciences, World Wide Web Consortium etc.);

- O formato de dados deve ser genérico e amplamente aceito, o que garante a disponibilidade de software de apresentação em plataformas de hardware correntes e futuras;

- O formato de dados deve estar livre de patentes ou taxas;

- Na medida do possível, documentos compostos (documentos que contêm diferentes tipos de dados) devem conter formatos padronizados;

- A definição e manutenção de formatos de arquivo adequados a estratégias de preservação exige solução híbrida, que combine questões tecnológicas e gerenciais (equipe multidisciplinar é requisito para um bom planejamento);

- Adoção de um ambiente padrão, o qual deve ser continuamente revisado e atualizado;

- Prevenção de risco de falsificação: recomenda-se manter versões antigas de documentos vitais ou de um conjunto importante de documentos;

- Planejamento de estruturas de metadados: recomenda-se incluir, no mínimo, dados sobre características técnicas do documento, sobre os critérios de seleção para 
preservação, registros catalográficos, palavras-chave, códigos de arquivo e de planos de classificação, dentre outros;

- Evitamento de soluções estritamente tecnológicas, fornecidas por fabricantes ou empresas, e soluções ad hoc, pois a migração não é um processo único e não consiste em métodos precisamente definidos.

\section{A.2-Recomendações para a seleção de formatos digitais}

As funções para definição de formatos de arquivos adequados ao PPD em curso estão relacionadas aos seguintes fatores de avaliação a considerar: a) fatores de sustentabilidade; b) fatores de qualidade e de funcionalidade.

\section{A.2.1) Fatores de sustentabilidade}

Os fatores de sustentabilidade aplicam-se a formatos digitais de todas as categorias e são significativos independente das diferentes estratégias adotadas para preservação, que podem ser: migração, emulação de software e de equipamentos, ou abordagem híbrida. Influenciam a viabilidade e o custo do conteúdo preservado face as mudanças no ambiente tecnológico em que usuários e instituições desempenham suas atividades. Os sete fatores de sustentabilidade são:

i. Disseminação: relativo à existência de especificações completas e de ferramentas para validar a integridade técnica, as quais devem estar acessíveis para os responsáveis que criam e que sustentam o conteúdo digital.

ii. Adoção: relativo ao uso corrente do formato pelos produtores, disseminadores e usuários de recursos de informação; inclui-se ainda o uso de um formato-mestre para distribuição a usuários finais e meios de intercâmbio entre sistemas.

iii. Transparência: relativo a possibilidades que a representação digital oferece para análise direta com ferramentas básicas, tais como legibilidade por pessoas usando apenas um editor de texto simples.

iv. Documentação: objetos digitais documentados contêm metadados descritivos, técnicos e administrativos.

v. Dependência externa: relativo ao grau que um formato depende de hardware, sistema operacional ou software para representação e uso, bem como estimativa da complexidade em lidar com tais dependências em ambientes futuros.

vi. Impacto de patentes: relativo à habilidade das instituições em sustentar um formato controlado por patentes. 
vii. Mecanismos de proteção técnica: relativo à existência e implementação de mecanismos, tais como criptografia, que impedem a preservação de conteúdo através de um repositório designado.

\section{A.2.2) Fatores de qualidade e de funcionalidade}

Fatores relacionados à habilidade do formato em representar características significativas exigidas por usuários finais ou futuros, em relação ao conteúdo específico. Tais fatores variam em gêneros particulares ou em formas de expressão do conteúdo. Por exemplo, características de formatos para sons são diferentes daquelas dos formatos para figuras, e nem todos os formatos para imagens são apropriados para todos os gêneros de imagens estáticas.

As expectativas dos usuários estabelecem a representação normal para um dado gênero ou forma de expressão do conteúdo. Representações normais são o fundamento para o comportamento do conteúdo, quando ele é apresentado ao usuário. Por exemplo, imagens que permitem zoom; sons que podem ser tocados, parados ou reiniciados etc.

\section{$\underline{B}$ - Formatos recomendados para preservação}

\section{B.1-Imagens estáticas}

\section{B.1.1- Identificação e descrição}

\begin{tabular}{|c|c|}
\hline Nome completo & TIFF (Tagged Image File Format), Revisão 6.0 \\
\hline Descrição & $\begin{array}{l}\text { Um formato de arquivo baseado em marcas para armazenamento e } \\
\text { para intercâmbio de imagens. Serve como extrator de diferentes } \\
\text { codificações para imagens mapeadas em bits. Tais codificações } \\
\text { representam diferentes esquemas de compressão para representação } \\
\text { de cores. }\end{array}$ \\
\hline Variações & $\begin{array}{l}\text { TIFF, Revision } 6.0 \text { and earlier } \\
\text { TIFF_G4, TIFF Bitmap with Group } 4 \text { Compression } \\
\text { TIFF_LZW, TIFF Bitmap with LZW Compression } \\
\text { TIFF_UNC, TIFF Uncompressed Bitmap } \\
\text { TIFF_UNC_EXIF, TIFF Uncompressed File with Exif Metadata } \\
\text { TIFF/IT, TIFF/IT, for Image Technology (Prepress) }\end{array}$ \\
\hline Fase de produção & $\begin{array}{l}\text { Um formato usado, na maioria dos casos, para o estado inicial, } \\
\text { mas que pode servir como estado final. }\end{array}$ \\
\hline Versão anterior & TIFF, Revisão 5.0. A versão TIFF atual é a 6.0 e foi em 1992. \\
\hline
\end{tabular}

Figura A1: descrição de formatos para imagens estáticas 


\section{$\underline{\text { B.1.2- Fatores de sustentabilidade }}$}

\begin{tabular}{|c|c|}
\hline Disseminação & $\begin{array}{l}\text { Documentação completa. TIFF foi desenvolvido pela Aldus e } \\
\text { Microsoft, e a especificação é mantida pela Aldus (integrada a Adobe } \\
\text { Corporation). }\end{array}$ \\
\hline Documentação & $\begin{array}{l}\text { TIFF, Revision 6.0, Final - June 3, } 1992 \\
\text { (http://partners.adobe.com/public/developer/en/tiff/TIFF6.pdf)TIFF } \\
\text { 5.0 Aldus/Microsoft Technical Memorandum: } 8 / 08 / 88 \\
\text { (http://palimpsest.stanford.edu/bytopic/imaging/std/tiff5.html) }\end{array}$ \\
\hline Adoção & $\begin{array}{l}\text { Subtipos específicos amplamente utilizados como formatos- } \\
\text { mestres para imagens digitalizadas. Não suportado por todos os } \\
\text { navegadores em formato nativo, mas desde } 2004 \text { as novas } \\
\text { configurações incluem um visualizador. } \\
\text { O formato é amplamente suportado por aplicações de manipulação } \\
\text { de imagens (como o Adobe Photoshop e outros), por aplicações } \\
\text { desktop e por aplicações de digitalização, OCR-optical character } \\
\text { recognition etc. }\end{array}$ \\
\hline Licenças e patentes & Não explorado. \\
\hline Transparência & Depende de codificação bit-stream. \\
\hline Documentação & Documentado, http://partners.adobe.com/public/developer/en/tiff/TIFF6.pdf \\
\hline Dependências externas & Não se aplica. \\
\hline Proteção técnica & Não se aplica. \\
\hline
\end{tabular}

Figura A2: fatores de sustentabilidade para imagens estáticas

\section{B.1.3- Fatores de qualidade e funcionalidade}

\begin{tabular}{|l|l|}
\hline $\begin{array}{l}\text { Apresentação normal } \\
\text { (para imagens estáticas) }\end{array}$ & Oferece suporte. \\
\hline $\begin{array}{l}\text { Clareza (suporte para } \\
\text { imagens de alta } \\
\text { resolução) }\end{array}$ & $\begin{array}{l}\text { Suporte excelente para imagens como alta resolução espacial. O padrão } \\
\text { apresenta uma escala de cinza de 8-bits, escala de cores RGB de 24-bits. }\end{array}$ \\
\hline Manutenção de cores & $\begin{array}{l}\text { Marcação TIFF para perfil ICC (The TIFF tag for the ICC profile, tag } \\
\text { 34675, InterColourProfile) relativa a dispositivos de captura que tem } \\
\text { sido usada como uma extensão proprietária em padrões TIFF/IT e } \\
\text { TIFF/EP. O Adobe Photoshop fornece alternativas para inserção do } \\
\text { perfil ICC em um arquivo TIFF. O espaço de cores é indicado } \\
\text { Photometric Interpretation (tag 262) TIFF_6. }\end{array}$ \\
\hline $\begin{array}{l}\text { Suporte a efeitos } \\
\text { gráficos }\end{array}$ & \begin{tabular}{l} 
Não oferece suporte para gráficos vetoriais. \\
\hline Extensão
\end{tabular} \\
\hline
\end{tabular}

Figura A3: fatores de qualidade para formatos de imagens estáticas 


\section{CONSIDERAÇÕES FINAIS}

Neste artigo descreveu-se brevemente as principais estratégias de preservação digital migração, emulação e encapsulamento -, bem como exemplos de iniciativas internacionais e nacionais. Também apresentou-se uma metodologia para criação de programas de preservação digital em instituições publicas. A metodologia completa considera como principal estratégia, em particular, a migração, e envolve pelo menos sete passos, elencados a seguir:

a) apresentação do PPD na instituição;

b) estabelecimento de princípios para o PPD na instituição;

c) definição da estrutura gerencial do PPD;

d) definição de alçadas e autoridade;

e) definição de documentos de controle do PPD;

f) recursos para manutenção do PPD;

g) estabelecimento de requisitos para implantação do PPD na instituição.

Além disso, apresentou-se um exemplo de aplicação da metodologia genérica para preservação de documentos com a criação de documentos contendo diretrizes sobre formatospadrão de documentos digitais para um programa em instituição do estado de Minas Gerais.

A metodologia apresentada é de alto nível, no sentido de que a definição das particularidades de cada instituição participante do programa é desenvolvida pela própria instituição, em conjunto com um grupo de apoio proveniente de orgãos executivos (secretarias de planejamento, por exemplo) e órgãos técnicos (arquivos públicos, por exemplo). Essa é a finalidade das comissões criadas no âmbito do programa e que se sobrepõem às funções gerenciais nas instituições. As comissões têm cargos e funções pré-determinadas, bem como alçadas e autoridades, e contam com um conjunto de documentos de controle padronizado, que permite controlar um grande número de processos nas instituições de acordo com alguns poucos padrões.

Cada comissão local corresponde à delimitação de um universo institucional que deseja implantar o programa. No exemplo apresentado, a comissão local foi a Diretoria Central de Contagem de Tempo e Aposentadoria (DCCTA), ligada à Secretaria de Planejamento de Estado. No âmbito dessa diretoria, foram criados procedimentos gerais a partir de um conjunto genérico que organiza o programa. No exemplo, descreveu-se o resultado da implantação do PG7, que versa sobre o formato de arquivos digitais. Esse 
conjunto genérico que organiza o programa corresponde ao mínimo necessário e é mantido pela comissão central, ligada aos órgãos executivo e técnico. Além dos procedimentos gerais, a instituição ainda tem a liberdade de criar procedimentos específicos e instruções normativas para atender às suas particularidades.

Dessa forma, todos os documentos criados no âmbito do programa permanecem alinhados com os procedimentos gerais, cargos, com as alçadas e autoridades definidas pela comissão central. Considerando a existência de procedimentos gerais que organizam o esquema de auditorias e as verificações (por exemplo, o PG6 e o PG8), é possível entender como esse reduzido número de princípios gerenciais pode ser expandido para controlar um grupo de instituições estaduais, mantendo-se um controle mínimo e garantindo-se a qualidade do processo.

Apresentada a metodologia e um exemplo de aplicação, cabe ainda enfatizar aspectos que recomendam iniciativas como a do Estado de Minas Gerais. Exemplos de perdas de dados digitais são comuns em todo o mundo, mas alguns casos merecem destaque: as fotos de satélites da NASA dos anos 70, que documentavam as condições da floresta amazônica brasileira estão irremediavelmente perdidas, assim como dados do censo americano de 1960 (BORGHOFF et al, 2003). Mais importante, no processo de reconhecimento da gravidade do problema, foi o estabelecimento das principais questões e soluções sobre preservação digital no âmbito do Unesco Charter on the Preservation of the Digital Heritage ${ }^{10}$, o que constatou que o problema não poderia mais ser ignorado.

Em relação às estratégias, que são uma parte do problema, fica em aberto a questão sobre qual delas é a mais adequada. De fato, ao mesmo tempo em que a estratégia de migração parece ser presença obrigatória em qualquer programa, a estratégia de encapsulamento não parece menos importante para soluções mais definitivas. A emulação parece ser uma estratégia que demanda altos recursos financeiros e técnicos, que talvez não estejam disponíveis no caso da realidade brasileira. Ao que parece, uma combinação delas é o panorama que se vislumbra como o mais adequado. A metodologia apresentada, que combina aspectos técnicos, de gestão e da arquivística parece ser um bom começo para organizar a necessidade de preservar documentos, mesmo que ainda não se tenha experiência sobre qual é a melhor forma.

\footnotetext{
${ }^{10}$ Disponível na Internet em : <http://unescodoc.unesco.org/images/0013/001311/131178e.pdf $>$. Acesso 30 Jun. 2010. 128
} 


\section{REFERÊNCIAS}

ALMEIDA, M. B.; NEVES, M. E. M.; TEIXEIRA, L. M. D. Proposta para programa de preservação de documentos de arquivo em formato digital a longo prazo do Estado de Minas Gerais. Belo Horizonte: Secretaria de Estado de Planejamento e Gestão MG. 2008. 244 p. Relatório.

BEARMAN, D.; SOCHATS, K. Functional Requirements for Evidence in Recordkeeping: The Pittsburgh Project. 2002 Disponível em: $<$ http://www.archimuse.com/papers/nhprc/BACartic.html>. Acesso: 20 jan. 2007.

BORGHOFF, U.M. et al. Long-Term preservation of digital documents: Principles and practices. New York: Springer, 2003. 274 p.

BULLOCK, A. Preservation of Digital information: Issues and Current Status. 1999. Disponível em: <http://epe.lac-bac.gc.ca/100/202/301/netnotes/netnotes-h/notes60.htm >. Acesso em: 06 out. 2008.

CEDARS Project. Cedars Guide to Digital Preservation Strategies. 2002. Disponível em: $<$ http://www.leeds.ac.uk/cedars/guideto/dpstrategies/>. Acesso em: 6 março 2009.

CLANCHY, M.T. From Memory to Written Record: England, Malden: Wiley-Blackwell, 1993. 407p.

CONSULTATIVE COMMITTEE FOR SPACE DATA SYSTEMS (CCSDS). Reference model for an Open Archival Information System (OAIS) - recommendation. 2002. Disponível em: <http://www.ccsds.org/documents/650x0b1.pdf > . Acesso: 14 setembro 2008.

CUNDIFF, M.V. An introduction to the Metadata Encoding and Transmission Standard (METS). Library Hi Tech, v. 22, n. 1, p. 52-64, 2004.

DURANTI, L. An Overview of InterPARES 3 (2007-2012). Archives \& Social Studies: A Journal of Interdisciplinary Research, v. 1, n. 2, p. 577-603, 2007.

DCMI. Dublin Core Metadata iniciative. Disponível em: $<$ http://dublincore.org/>. Acesso em: 12 jun. 2010.

HEDSTROM, M. Digital Preservation: a time bomb for digital libraries. Language Resources and Evaluation, v. 31, n.3, p. 189-202, 1997.

IKEMATU, R. S. 2001. Gestão de Metadados: sua evolução na tecnologia da informação. Datagramazero: Revista de Ciência da Informação, v. 2, n. 6, 2001.

INTERPARES Project. Walkthrough Applying The "Preserve Electronic Records" Model. 2001. Disponível em: < http://www.interpares.org/book/index.cfm>. Acesso em: 01 jan. 2008. 
INTERNATIONAL ORGANIZATION FOR STANDARTIZATION (ISO) (2008). ISO 9001:2008 Quality management systems - Requirements. Disponível em: $<\mathrm{http}$ ://www.iso.org/>. Acesso em 20 jan. 2004.

LUSENET, Y. Towards Open Access in Europe. 2007. Disponível em: $<$ http://www.knaw.nl/ecpa/publications.html>. Acesso em: 01 fev. 2010.

NATIONAL LIBRARY OF AUSTRALIA (NLA). The NLA Preservation Metadata Working Group. 1999. Disponível em: http://www.nla.gov.au/preserve/pmeta.html. Acesso em: 02 de nov. 2008.

PDF/A COMPETENCE CENTER. PDF / A Conference Center. 2009. Disponível em: http://74.125.93.132/search?q=cache:http://www.pdfa.org/>. Acesso em: 26 maio 2009.

THOMAZ, K. P. A preservação de documentos eletrônicos de caráter arquivístico. 388f. Doutorado em Ciência da Informação - Escola de Ciência da Informação. Belo Horizonte, 2004.

UNIVERSITY OF CALIFORNIA, SCHOOL OF INFORMATION MANAGEMENT AND SYSTEMS. How Much Information? 2003. Disponível em $<$ http://www2.sims.berkeley.edu/research/projects/how-much-info/summary.html\#intro>. Acesso em: 05 out. 2008 